\title{
IgM class antitreponemal antibody in treated and untreated syphilis
}

\author{
P. O'NEILL AND C. S. NICOL \\ From the Departments of Microbiology and Venereal Diseases, St. Thomas' Hospital, London, S.E.1.
}

It is a particular advantage of the indirect fluorescent antibody (IFA) method that antibodies of different immunoglobulin classes may be separately detected and measured by the use of monospecific antiglobulin conjugates. Matuhasi, Mizuoka, and Usui (1966), Király, Bachhausz, Jobbágy, Lajos, and Kováts (1968), Julian, Logan, and Norins (1969), and Atwood and Miller (1969) studied antibodies in syphilis using IFA methods, and are in general agreement that while reactivity in fluorescent treponemal antibody (FTA) tests is due mainly to IgG class antitreponemal antibody, antibodies of IgM and IgA classes also contribute. IgM class antitreponemal antibody, in particular, was present in nearly all sera from cases of early syphilis examined by these workers, but often absent or present only in small amounts in sera obtained later in the disease.

The purpose of the present study was to define more precisely the clinical significance of IgM class antibody to Treponema pallidum. 1,100 sera from patients with syphilis (both treated and untreated) were examined by the fluorescent treponemal antibody absorption (FTA-ABS) test for IgG class and IgM class anti- $T$. pallidum antibody. The observations permit conclusions about the clinical circumstances in which IgM class antibody detectable by FTA-ABS may be expected.

\section{Method and materials}

\section{REAGENTS}

$T$. pallidum antigen was obtained from three commercial sources: Baltimore Biological Laboratories, Wellcome Reagents Limited, and Difco Laboratories. We also gratefully acknowledge gifts of $T$. pallidum and $T$. reiteri from Dr. A. E. Wilkinson. Each batch of $T$. pallidum was assayed for antigenicity in both $\operatorname{IgG}$ and $\operatorname{IgM}$ systems by titration with stock reference sera. These control titrations were also included in every batch of tests, since variation

Received for publication April 14, 1972

A preliminary account of this work was read at the Annual Meeting of the M.S.S.V.D. at Lyons in May, 1971 in antigenicity of substrates can be a major source of error in the FTA-ABS procedure, particularly in the IgM system.

Sorbent was obtained from Baltimore Biological Laboratories.

Monospecific FITC-conjugated antihuman IgG and antihuman IgM were obtained from Wellcome Reagents Limited. Infant serum known to contain anti-T. pallidum antibody of $\mathrm{IgG}$ class only was used to confirm that the anti-IgM conjugate did not react with IgG under our test conditions.

\section{TEST PROCEDURE}

We used the microvolume semiautomated FTA-ABS technique described previously (O'Neill, Johnson, and Nicol, 1970; O'Neill and Johnson, 1971). Sera were screened at a dilution of 1 in 5 . Titrations were carried out on some sera, in which case serial dilutions were made in phosphate buffered saline, followed by a final 1 in 5 dilution in sorbent.

\section{CRITERIA OF SIGNIFICANCE}

Tests were judged reactive in both IgG and IgM systems, if fluorescence of $2+$ or greater intensity was seen. Preliminary FTA-ABS tests on sera from 150 healthy individuals and 150 presumed non-syphilitic hospital patients indicated that fewer than 1 per cent; of individuals give $2+$ IgM fluorescence under our test conditions.

\section{Clinical material}

All patients studied attended St. Thomas's Hospital Venereal Disease Clinic during the period May, 1968, to February, 1972. Many have continued to attend for follow-up.

\section{PATIENTS WITH UNTREATED SYPHILIS (128 cases)}

These were distributed as follows: Primary syphilis 54 cases, secondary syphilis 38 cases, early latent syphilis $\mathbf{2 1}$ cases, late syphilis 15 cases (5 latent, 5 symptomatic, 5 congenital). The numbers in the untreated late syphilis group are small because only patients with a clear history of having had no treatment were included. 
PATIENTS WITH TREATED SYPHILIS (267 cases)

201 patients presented with a history of treated syphilis. A further 66 patients who presented with untreated syphilis were transferred to the treated group after 3 months follow-up.

Patients from areas where yaws or other treponematoses are endemic were not included for study unless one of the following was present:

(i) a darkfield positive lesion;

(ii) stigmata of congenital disease;

(iii) a clear history of previously negative serological tests for syphilis.

\section{Results}

Patients with untreated syphilis

320 sera, from 128 cases of untreated syphilis, were tested by the FTA-ABS test. In every case but one, significant amounts of both IgM and IgG antibody were present. The exception was a man with very early primary syphilis in whom both IgM and IgG were detectable, but fluorescence was slightly less than $2+$. Titres of IgM in untreated cases were usually between 1 in 40 and 1 in 320. IgG titres, except in primary syphilis, were much higher, ranging from 1 in 320 to 1 in 10,240 or above.

Sera containing high titre IgG by the FTA-ABS test often gave rather weakly positive IgM fluorescence at the 1 in 5 screening dilution, although titration showed IgM to be present to quite high titre. This effect might be due to competition between IgG and IgM antibodies for antibody binding sites.

\section{Patients with treated syphilis}

871 sera were examined from 267 cases of treated syphilis. A clear correlation between the presence of IgM antibody by the FTA-ABS test and the time interval since treatment was apparent in the total figures, and was confirmed by serial observations on individual patients.
IgM STATUS AND TIME SINCE TREATMENT

\section{(i) All patients}

Table I shows FTA-ABS positivity rates related to time since treatment for all patients tested 6 months or more after treatment. IgM and IgG are shown separately.

6 to 11 months after treatment only half the patients tested still had IgM antibody by FTA-ABS test. At 12 to 23 months this had fallen to 20 per cent., and at 2 to 5 years to 13 per cent. 5 to 20 years after treatment the rate was 14 per cent.; 20 years or more after treatment it was 11 per cent.

In contrast, more than 85 per cent. of patients at all intervals since treatment had IgG antibody detectable by the FTA-ABS test. Even 20 years or more after treatment IgG was detectable in $\mathbf{4 6}$ out of 51 individuals (90 per cent.).

Shown separately in Table I are 79 patients who had had one episode of primary syphilis only. In this group, 77 per cent. of patients were FTA-ABS IgM negative at 6 to 11 months, 95 per cent. at 12 to 23 months, and 100 per cent. at 2 to 5 years. Nearly all of them continued to have IgG antibody detectable by the FTA-ABS test.

\section{(ii) Serial studies}

66 patients who presented untreated were tested at frequent intervals after treatment for up to $2 \frac{1}{2}$ years. In forty of these (Table II), the disappearance of IgM FTA-ABS antibody could be dated. We found that cases of seronegative primary syphilis remained IgM positive for 1 to 6 months after treatment (average 3 months). Treated seropositive primary cases remained IgM positive for 3 to 16 months (average 6); treated secondary and early latent cases remained IgM positive for 3 to 18 months (average 8).

We were unable to draw conclusions about the persistence of IgM class FTA-ABS antibody after

TABLE I FTA-ABS positivity rates related to time since treatment

\begin{tabular}{|c|c|c|c|c|}
\hline Interval since treatment & \multicolumn{4}{|c|}{ Percentage patients still reactive } \\
\hline \multirow[b]{2}{*}{ 6-11 mths } & FTA-ABS IgG & \multirow{2}{*}{$\frac{\text { FTA-ABS IgM }}{51}$} & FTA-ABS IgG & \multirow{2}{*}{$\frac{\text { FTS-ABS IgM }}{23}$} \\
\hline & $100(55)^{\mathrm{a}}$ & & $100 \quad(22)^{\mathrm{a}}$ & \\
\hline $12-23$ mths & $85(46)^{b}$ & 20 & $65(20)^{b}$ & 5 \\
\hline More than 20 yrs & $90 \quad(51)$ & 10 & 92 (13) & 0 \\
\hline
\end{tabular}

Number of patients shown in brackets

bIncludes seven patients treated very early in the primary stage 
TABLE II Duration of FTA-ABS IgM reactivity after treatment in forty patients followed serially

\begin{tabular}{|c|c|c|c|c|c|}
\hline \multicolumn{2}{|l|}{ Type of syphilis } & \multirow{2}{*}{ Seronegative primary } & \multirow{2}{*}{$\begin{array}{l}\text { Seropositive primary } \\
10 \\
\end{array}$} & \multirow{2}{*}{$\begin{array}{l}\text { Secondary } \\
10 \\
\end{array}$} & \multirow{2}{*}{$\frac{\text { Early latent }}{11}$} \\
\hline No. of patients & & & & & \\
\hline \multirow{2}{*}{$\begin{array}{l}\text { Duration of FTA-ABS } \\
\text { IGM reactivity (mths) }\end{array}$} & Average & 3 & 6 & 8 & 8 \\
\hline & Range & $1-6$ & $3-16$ & $3-18$ & $3-12$ \\
\hline
\end{tabular}

the treatment of late syphilis because of the small number of cases studied. Of four adults presenting with untreated congenital syphilis, two became IgM negative within 16 months of treatment, and two (still under follow up) remain positive after 6 and 15 months respectively. None of 23 cases of congenital syphilis tested $2 \frac{1}{2}$ years or more after treatment had IgM antibody by the FTA-ABS test.

\section{SPECIFICITY OF IgM CLASS FTA-ABS ANTIBODY}

IgM antibody detected by the FTA-ABS test (using sorbent, not sonicate) was not specific for $T$. pallidum. Significant fluorescence was observed when $T$. reiteri was used as substrate, and the reaction with $T$. reiteri was not blocked by excess Reiter protein.

\section{IgM CLASS FTA-ABS ANTIBODY AND REAGIN ANTIBODY}

Antibody to lipoidal antigens (reagin antibody) was present in eighty of 190 patients tested 2 years or more after treatment; only thirteen of these eighty patients had persistent IgM. Conversely, seven of 23 patients with persistent IgM antibody by the FTA-ABS test had no detectable reagin antibody.

\section{Discussion}

It appears that most patients treated for syphilis cease producing IgM antibody to $T$. pallidum quite soon after treatment, usually within months. IgG production, on the other hand, generally continues for many years.

A minority of patients, however, continue to produce IgM anti-treponemal antibody long after treatment, and a possible explanation for this is that the patients concerned have relapsed or become re-infected. The following observations would suggest that re-infection plays a part in some cases:

(i) Persistent IgM was not seen in any of the 79 cases of treated primary syphilis shown in Table I. There was no clinical or conventional serological evidence of re-infection in any of these cases.

(ii) None of 23 cases of treated late congenital syphilis had persistent IgM antibody by the FTAABS test. None of these patients is known to be promiscuous, and at least five of them are not sexually active.

(iii) 23 per cent. of 61 homosexual men tested 2 years or more after treatment had persistent IgM antibody. This is almost double the incidence in the group as a whole (12 per cent.). It is recognized that in London at present male homosexuals run a particular risk of infection (or re-infection) with syphilis.

(iv) Five patients with persistent $\operatorname{IgM}$ were re-treated and all became IgM negative within 7 months.

An apparent persistence of $\operatorname{IgM}$ class antitreponemal antibody might be due in some instances to the presence in the serum of antiglobulin antibody of IgM class. This possibility is being examined and will be the subject of a separate report.

Whatever the reason for the persistence of $\operatorname{IgM}$ antibody in some patients with treated syphilis, the data as a whole suggest that arrest of disease is associated with the disappearance of IgM class FTAABS antibody. A knowledge of this association is helpful in the management of new patients with positive serological tests. Thus patients with positive tests who lack IgM class FTA-ABS antibody are likely to be cases of treated treponemal disease, and the history usually confirms that this is so. It is suggested that further action may be unnecessary in such patients. On the other hand, patients with positive serological tests who do have IgM class FTA-ABS antibody may be untreated, inadequately treated, recently treated, or possibly re-infected. These patients, except those with a history of recent adequate therapy, may require treatment.

Although clearly a potentially useful test, the actual contribution of the IgM FTA-ABS test to patient management will depend upon the availability of the test to clinicians. It must be emphasized that this is not an easy test to perform. It requires very strict control of reagents and test procedures, and highly trained observers. Also, at present, suitable reagents are not widely available. However, centres with sufficient resources to enable them to operate the test are likely to find it valuable in routine clinic practice. 


\section{Summary}

Sera from 267 patients with treated syphilis and 128 patients with untreated, mainly early, syphilis were examined for IgM class antitreponemal antibody by the FTA-ABS test. All samples from untreated patients contained IgM class antitreponemal antibody, but only 12 per cent. of patients tested 2 years or more after treatment were IgM positive. The significance of these findings, and their possible application to clinical management, are discussed.

\section{References}

Atwood, W. G., and Miller, J. L. (1969) Arch. Derm., 100, 763

Király, K., Backhausz, R., Jobbágy, A., Lajos, J., and KovÁts, L. (1968) Acta derm.-venereol. (Stockh.), 48, 362

Julian, A. J., Logan, L. C., and Norins, L. C. (1969) F. Immunol., 102, 1250
Matuhasi, T., Mizuoka, K., and Usui, M. (1966) Bull. Wld Hlth Org., 34, 466

O'Neill, P., and Johnson, G. D. (1971) Ann. N.Y. Acad. Sci., 177, 446

,-- , and Nicol, C. S. (1970) Brit. F. vener. Dis., 46, 278

\section{L'anticorps antitréponémique de la classe IgM dans la syphilis traitée et non traitée}

\section{SOMMAIRE}

Les sérums de 267 syphilitiques traités et de 128 non traités atteints principalement de syphilis récente furent examinés pour étudier l'anticorps antitréponémique de la classe IgM par le test FTA-ABS. Tous les sérums des malades non traités contenaient un anticorps antitréponémique de la classe $\mathrm{IgM}$ mais seulement 12 pour cent des malades testés deux ans ou plus après traitement furent IgM positifs. On discute de la signification de ces constatations et de leur application possible en clinique. 